\title{
artigo
}

Costa, R.A.; Mendes, G.V.; Andrade, N.C.M.; Alves, M.E.F.; Siqueira, J.M., Farias, S.N.P.; Cavalcante, A.C.A.;

A educação para saúde realizada por enfermeiros acerca das arboviroses no Brasil

\section{A educação para saúde realizada por enfermeiros acerca das arboviroses no Brasil}

\author{
Health education performed by nurses about arboviroses in Brazil \\ Educación en salud realizada por enfermeras sobre arbovirosis en Brasil
}

\begin{abstract}
RESUMO
O presente trabalho tem como objetivo verificar a produção científica acerca do papel do enfermeiro como educador em Saúde no âmbito das arboviroses. Foram encontrados 444 artigos, após aplicação dos critérios de inclusão e exclusão, foram selecionados 6 artigos, com o idioma em português, nas bases de dados LILACS e BEDENF. Indubitavelmente, os artigos apontaram há desinformação por parte da população e ainda, que há necessidade dos profissionais de enfermagem e o governo realizarem ações para reforçar as formas de prevenção das arboviroses, nesse sentido, observou-se a escassez de estudos que retratassem a atuação da enfermagem na educação em saúde sobre arboviroses. Ressaltaram-se os estudos sobre o tema Dengue em detrimento das demais arboviroses. Assim, faz-se necessário o investimento em atividades de pesquisa e extensão, e ações educativas para promoção da saúde, para o controle das doenças transmitidas pelo Aedes Aegyptie subsídio da prática baseada em evidências da enfermagem.
\end{abstract}

DESCRITORES: Enfermagem; Educação em Saúde; Dengue; Febre Zika; Febre Amarela; Chikungunya Vírus.

\section{ABSTRACT}

The present work aims to verify the scientific production about the nurse's role as a health educator in the scope of arboviruses. 444 articles were found, after applying the inclusion and exclusion criteria, 6 articles were selected, with the language in Portuguese, in the LILACS and BEDENF databases. Undoubtedly, the articles pointed out that there is misinformation on the part of the population and that there is a need for nursing professionals and the government to take actions to reinforce the ways of preventing arboviruses, in this sense, there was a scarcity of studies that portrayed the performance of nursing in health education on arboviruses. Studies on the topic of Dengue were emphasized at the expense of other arboviruses. Thus, it is necessary to invest in research and extension activities, and educational actions for health promotion, for the control of diseases transmitted by Aedes Aegypti and support for evidence-based nursing practice.

DESCRIPTORS: Nursing; Health Education; Dengue; Zika Fever; Yellow Fever; Chikungunya Virus.

\section{RESUMEN}

El presente trabajo tiene como objetivo verificar la producción científica sobre el papel de la enfermera como educador de salud en el ámbito de los arbovirus. Se encontraron 444 artículos, después de aplicar los criterios de inclusión y exclusión, se seleccionaron 6 artículos, con el idioma en portugués, en las bases de datos LILACS y BEDENF. Sin lugar a dudas, los artículos señalaron que existe una información errónea por parte de la población y que es necesario que los profesionales de enfermería y el gobierno tomen medidas para reforzar las formas de prevenir los arbovirus, en este sentido, hubo una escasez de estudios que retrataran el desempeño de enfermería en educación sanitaria en arbovirus. Se enfatizaron los estudios sobre el tema del dengue a expensas de otros arbovirus. Por lo tanto, es necesario invertir en actividades de investigación y extensión, y acciones educativas para la promoción de la salud, el control de enfermedades transmitidas por Aedes Aegypti y el apoyo a la práctica de enfermería basada en evidencia. DESCRIPTORES: Enfermería; Educación en Salud; Dengue Fiebre del Zika; Fiebre Amarilla; Virus Chikungunya.

RECEBIDO EM: 13/02/2020 APROVADO EM: 14/02/2020

\section{Rachel de Araujo Costa}

Graduanda da Escola de Enfermagem Anna Nery - UFRJ. https://orcid.org/0000-0003-0564-3585

Giovanna Vivacqua Mendes

Graduanda da Escola de Enfermagem Anna Nery - UFRJ. https://orcid.org/0000-0002-6081-3260 


\section{Nathalia da Costa Melo de Andrade}

Graduanda da Escola de Enfermagem Anna Nery - UFRJ. https://orcid.org/0000-0002-3837-3924

\section{Maria Eduarda Fernandes Alves}

Graduanda da Escola de Enfermagem Anna Nery - UFRJ. https://orcid.org/0000-0001-8138-7443

Janaina Moreno de Siqueira

Enfa. Mestranda da Escola de Enfermagem Anna Nery - UFRJ. https://orcid.org/0000-0002-9806-6352

\section{Sheila Nascimento Pereira de Farias}

Profa. Dra. da Escola de Enfermagem Anna Nery - UFRJ. https://orcid.org/0000-0001-5752-265X

\section{Anna Carolina de Araújo Cavalcante}

Graduanda da Escola de Enfermagem Anna Nery - UFRJ. https://orcid.org/0000-0003-4885-7321

\section{INTRODUÇÃO}

A s arboviroses têm representado, nas últimas décadas, um problema de grande relevância em Saúde Pública nas Américas, bem como em todo o mundo. Tratam-se de infecções virais causadas pelos chamados "arbovírus" (do inglês, "arthropode-borne virus"), vírus essencialmente transmitidos por vetores artrópodes hematófagos. Atualmente, estima-se que exista, aproximadamente, 545 espécies de arbovírus e que, cerca de 150 destas, possam causar doenças infecciosas em humanos ${ }^{(1)}$.

De acordo com um estudo feito pelo Instituto Evandro Chagas ${ }^{(2)}$, a emergência e disseminação das infecções arbovirais se deve a alguns principais fatores, tais como: o crescimento populacional, a urbanização sem planejamento e a derrubada de floresta, além do aumento do tráfego humano e do comércio internacional, sendo um problema de dimensão mundial em Saúde Pública devido à dispersão territorial que alcançara, requerendo, portanto, ações de prevenção e controle mais complexas; contudo, as condições ambientais e climáticas favoráveis também são importantes fatores determinantes para o desenvolvimento e proliferação dos vetores destas infecções, sendo, por esta razão, uma problemática mais incidente nos países tropicais.

O Brasil, por ser predominantemente tropical, possui clima propício à manutenção e circulação dos vetores. A população brasileira, por sua vez, proporciona, continuamente, a formação de habitats artificiais para a desova e o desenvolvimento destes artrópodes, devido ao descuido dos indivíduos para com as condições ambientais. Como consequência, as arboviroses encontram-se associadas a grandes epidemias no país, sendo relevante o número de pessoas infectadas a cada ano.

Os principais arbovírus envolvidos nas epidemias que assolam o território brasileiro são os flavivírus - responsáveis por causarem na população as duas principais infecções: dengue e febre por vírus zika e, mais recentemente, a febre amarela - e os alphavírus - gênero causador dos casos de febre chikungunya. Todas as infecções causadas por estes gêneros no país são intermediadas por um vetor em comum: o mosquito fêmea da espécie Aedes aegypti, a principal espécie vetor que aparece neste contexto.

A dengue (DEN) é considerada a infecção arboviral mais incidente em todo o mundo, sendo responsável por diversos casos de óbito anualmente. Segundo o Boletim Epidemiológico de 2003-2019 do Ministério da Saúde (MS), no período de 2003 a maio de 2019, foram notificados 11.137.664 casos prováveis de DEN no Brasil. No país, a primeira epidemia de DEN documentada clínica e laboratorialmente ocorreu em 1981 e 1982, no entanto, desde esta época até os dias de hoje, já ocorreram quatro grandes epidemias no país, sendo estas em 1998, 2002, 2008 e 2010, respectivamente. Atualmente, a incidência desta infecção no país encontra-se sob maior controle, mas, apesar disto, casos de morte por DEN ainda são comumente notificados, como mostra o Boletim Epidemiológico de 2003-2019 $9^{(3)}$.
A febre por vírus zika (ZIKA), por sua vez, mudou o cenário epidemiológico brasileiro de manifestações neurológicas. Após a detecção do vírus no país em abril de 2015, foi observado o aumento do número de encefalite, mielite, encefalomielite, síndrome de Guillain-Barré e, principalmente, de microcefalia em nascidos vivos, malformação congênita caracterizada pelo perímetro cefálico reduzido para a idade gestacional, acompanhada por alteraçôes no sistema nervoso central. Desde 2015, o número de microcefalia neonatal, possivelmente associada ao ZIKA, cresceu significativamente no Brasil. Cerca de 1.608 casos de microcefalia foram registrados somente no ano de 2015, número muito superior à média obtida nos anos anteriores ${ }^{(4)}$.

Os primeiros casos autóctones de chikungunya (CHIK) foram identificados pela primeira vez no Brasil em setembro de 2014, em Oiapoque no Estado de Amapá (Norte) e, Feira de Santana, Estado da Bahia (Nordeste). Sua manifestação um tanto diferente apresenta como característica de destaque, a artralgia, complicação que na fase crônica da doença é possivelmente incapacitante. Entre 2014 e 2019, ainda de acordo com o Boletim Epidemiológico de 2003-2019, foram notificados 589.076 casos prováveis e 495 óbitos por CHIK confirmados por laboratório.

A febre amarela (FEBR), doença há muito tempo esquecida no Brasil, teve uma manifestação de característica repentina. Isso porque, há anos não havia epidemias da doença no país até inúmeros casos aparecerem nos últimos anos, avançando 


\section{artigo}

Costa, R.A.; Mendes, G.V.; Andrade, N.C.M.; Alves, M.E.F.; Siqueira, J.M., Farias, S.N.P.; Cavalcante, A.C.A.;

A educação para saúde realizada por enfermeiros acerca das arboviroses no Brasil

por todo o território brasileiro. De acordo com o Boletim Epidemiológico 01 do MS, os maiores surtos da história da FEBR silvestre no Brasil - desde que esse ciclo de transmissão foi descrito na década de 1930 - , ocorreram nos anos de monitoramentos 2016/2017 e 2017/2018, quando foram registrados cerca de 2,1 mil casos e mais de 700 óbitos pela doença(5). Mas, apesar de se tratar de uma infecção potencialmente perigosa, diferente das demais arboviroses citadas, para o enfrentamento desta patologia, temos como estratégia de prevenção, a vacina, estratégia ainda muito temida e mistificada pela população.

Nota-se, portanto, neste cenário, a importância da atuação da Atenção Primária à Saúde (APS) no engajamento para a prevenção e controle das arboviroses. Uma vez que se tratam de infecções que podem ser facilmente prevenidas e controladas através da conscientização da população em relação aos cuidados com as condições ambientais, a APS se faz de significativa relevância, tendo em vista que a APS é a principal porta de entrada do Sistema Único de Saúde (SUS), principalmente quando o foco está direcionado para a Educação em Saúde para a comunidade.

Neste sentido, a pretensão deste estudo baseou-se em identificar através de um levantamento bibliográfico na literatura científica, em produções nacionais e internacionais, evidências apoiadas na questão norteadora: "Como está sendo a atuação do enfermeiro como educador em saúde para a prevenção e controle das arboviroses?"; com finalidade de contribuir para uma prática assistência no âmbito da APS contextualizada em evidências científicas e também para a área da enfermagem voltada para projetos de pesquisa e extensão.

\section{METODOLOGIA}

O presente estudo trata-se de uma Revisão Integrativa (RI), um método de pesquisa bibliográfica que reúne informações e resultados obtidos de artigos publicados, ou seja, evidências científicas, apresentadas em forma de síntese, acerca de um determinado tema e dentro de um recorte temporal, com o intuito de dar suporte para uma assistência em saúde baseada em evidências.

A questão norteadora do estudo consiste na possível análise da atuação do enfermeiro como educador em saúde no âmbito das arboviroses já mencionadas, ou seja, "Como está sendo a atuação do enfermeiro como educador em saúde para a prevenção das arboviroses?".

Para o levantamento bibliográfico, foi realizada uma busca bibliográfica on-line em periódicos com indexações nacional e internacional, nas bases de dados: Literatura Latino-Americano e do Caribe em Ciências da Saúde (LILACS), Medical Literature Analysis and Retrieval System Online (Medline), Base de Dados em Enfermagem (BDENF), consultadas através do site da Biblioteca Virtual em Saúde (BVS) e também na Scientific Eletronic Library Online (SciELO).

$\mathrm{Na}$ busca pelos artigos foram utilizados descritores nos idiomas português, inglês e espanhol, sendo tais descritores: "Enfermagem", "Educação em Saúde", "Dengue", "Vírus Zika", "Vírus Chikungunya", "Febre Amarela", "Nursing", "Health Education", "Dengue", "Zika Vírus", "Chikungunya Vírus", "Yellow Fever", "Enfermería", "Educación em Salud", "Dengue", "Vírus Zika", "Vírus Chikungunya", "Fiebre Amarilla". Além da utilização de três idiomas distintos, cada descritor combinado a outro descritor de mesmo idioma com o emprego do operador booleano "AND", em cada uma das bases de dados referidas anteriormente.

Após a busca nas bases com os descritores selecionados, como critérios de inclusão, foram utilizados da amostra da RI: artigos completos e disponíveis na íntegra, publicados no período entre 2014 e 2018, contendo os descritores da RI no título ou no resumo, artigos científicos originais e revisões, e artigos em que o país em menção fosse o Brasil. Foram excluídos: os artigos identificados em mais de uma base, teses, monografias e livros.

O total de estudos encontrados foi de 444 artigos, sendo a maioria publicada na língua inglesa e encontrada na Medline. Com a aplicação dos critérios de exclusão, os artigos foram avaliados, sendo excluídos os que não tratavam do tema da RI em seu resumo e que não tinham nenhum dos descritores entre as palavras-chave.

Nessa fase da seleção, após a exclusão dos artigos que não se adequavam, foram encontrados 22 artigos, os quais foram lidos na íntegra, sendo descartados após a leitura analítica 16 destes que não atendiam aos critérios de inclusão da RI, compondo a amostra final da RI somente 6 artigos.

Para melhor visualização de todo o processo de seleção da amostra deste estudo, foi elaborado o fluxograma apresentado na Figura 1:

Figura 1. Fluxograma da Rl, seleção de artigos nas bases de dados. Rio de Janeiro, RJ, Brasil, 2019.

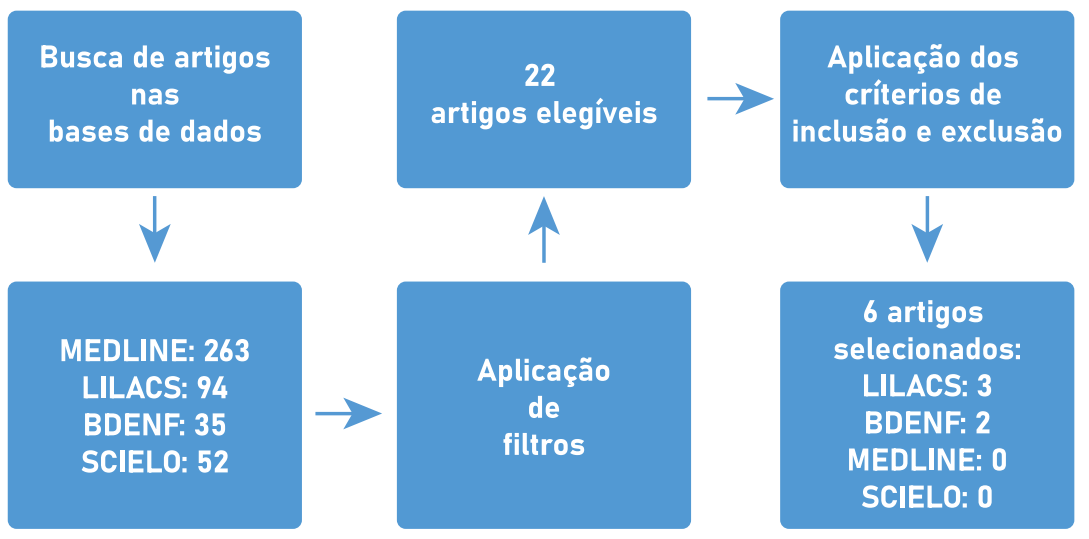




\section{RESULTADOS}

A amostra do estudo foi composta por seis artigos e a apresentação dos resultados encontrados está estruturada desta forma: o Quadro 1 apresenta a caracterização dos artigos elegíveis à RI segundo o número de identificação do artigo, ano de publicação, autor(es), o título da publicação, o periódico, o país de origem, o idioma e base de dados; e, no Quadro 2 estão dispostos o número de identificação do estudo, seus objetivos, o tipo de estudo, resultados, conclusões e recomendações.

O Quadro 1 apresenta estudos publicados durante o período de 2014 a 2018, recorte temporal definido para a pesquisa realizada. Os anos de 2016 e 2017 concentraram o maior quantitativo de publicações, com um total de dois cada um, seguido pelos anos de 2014 e 2015. No ano de 2018 , não foi realizada qualquer produção sobre o tema na forma de artigo científico. Foi detectado que todos os estudos possuíam mais de três autores. Em relação ao país de origem, todos os artigos foram publica- dos no Brasil. O idioma predominante foi o português e não foram encontrados estudos em inglês ou em espanhol. À análise das bases de dados, a LILACS concentrou quatro publicações que subsidiaram a presente pesquisa, representando $66,6 \%$ de um total de $100 \%$ dos dados.

O Quadro 2 apresenta a caracterização dos artigos da RI. Quanto aos objetivos, os estudos revisados retratam, em sua mmaioria (três estudos) sobre o enfrentamento da DEN.

Do total da amostra, um estudo tem entre seus objetivos analisar a atuação do

\section{Quadro 1. Caracterização da amostra de artigos da RI. Rio de Janeiro, RJ, Brasil, 2014 - 2018.}

\begin{tabular}{|c|c|c|c|c|c|c|c|}
\hline $\mathbf{N}^{0}$ & ANO & AUTOR(ES) & TÍTULO & PERIÓDICO & PAís & IDIOMA & $\begin{array}{l}\text { BASE DE } \\
\text { DADOS }\end{array}$ \\
\hline 01 & 2015 & $\begin{array}{l}\text { Ronaldo Pinheiro Gonçalves, } \\
\text { Edilmar Carvalho de Lima, } \\
\text { José Wellington de Oliveira } \\
\text { Lima, Marcelo Gurgel Carlos } \\
\text { da Silva, Andrea Caprara }\end{array}$ & $\begin{array}{l}\text { Contribuições recentes sobre } \\
\text { conhecimentos, atitudes e } \\
\text { práticas da população brasi- } \\
\text { leira acerca da dengue }\end{array}$ & Saúde Soc & Brasil & Português & LILACS \\
\hline 02 & 2016 & $\begin{array}{l}\text { Franklin Learcton Bezerra } \\
\text { de Oliveira, Rejane Medeiros } \\
\text { Millions, Marcelo Viana da } \\
\text { Costa, José Jailson de Almeida } \\
\text { Júnior, Dany Geraldo Kramer } \\
\text { Cavalcanti e Silva. }\end{array}$ & $\begin{array}{l}\text { Estudo comparativo da atua- } \\
\text { ção do enfermeiro no controle } \\
\text { de dengue e febre chikungunya }\end{array}$ & Saúde Soc & Brasil & Português & LILACS \\
\hline 03 & 2016 & $\begin{array}{l}\text { Gabriel Augusto Cordeiro } \\
\text { Dos Santos, Jacqueline Da } \\
\text { Silva Rosa, Eliseth Costa Oli- } \\
\text { veira De Matos, Mary Eliza- } \\
\text { beth De Santana. }\end{array}$ & $\begin{array}{l}\text { Dengue: Prevenção, Controle e } \\
\text { Cuidados de Enfermagem - } \\
\text { Revisão Integrativa da Litera- } \\
\text { tura 2008-2013 }\end{array}$ & $\begin{array}{l}\text { Revista } \\
\text { Brasileira de } \\
\text { Ciências da } \\
\text { Saúde }\end{array}$ & Brasil & Português & LILACS \\
\hline 04 & 2017 & $\begin{array}{l}\text { Luciane Abrantes Nicácio, } \\
\text { Rejane Marie Barbosa Da- } \\
\text { vim, Moisés Barbosa Oli- } \\
\text { veira, José Cleston de Farias } \\
\text { Camboim, Hellen Renatta } \\
\text { Leopoldino Medeiros, Silvia } \\
\text { Ximenes Oliveira }\end{array}$ & $\begin{array}{l}\text { Intervenção educativa sobre } \\
\text { o mosquito Aedes aegypti } \\
\text { em escolares: possibilidade } \\
\text { para a enfermagem no con- } \\
\text { texto escolar }\end{array}$ & $\begin{array}{l}\text { Revista de } \\
\text { enfermagem } \\
\text { UFPE online }\end{array}$ & Brasil & Português & BDENF \\
\hline 05 & 2017 & $\begin{array}{l}\text { Aparecida Maria da Silva } \\
\text { Affini1, Sergio Neder Ro- } \\
\text { cha, Simone Albino da Silva, } \\
\text { Eliana Peres Rocha Carvalho } \\
\text { Leite, Fábio de Souza Terra, } \\
\text { Mônica Lá-Salette da Costa } \\
\text { Godinho, et al }\end{array}$ & $\begin{array}{l}\text { Condutas das enfermeiras } \\
\text { sobre o Zika Vírus na consulta } \\
\text { pré-natal }\end{array}$ & $\begin{array}{l}\text { Revista de } \\
\text { enfermagem } \\
\text { UFPE online }\end{array}$ & Brasil & Português & BDENF \\
\hline 06 & 2014 & $\begin{array}{l}\text { Myrella Silveira Macedo Can- } \\
\text { çado, Maria Alves Barbosa, } \\
\text { Ricardo Antônio Gonçalves } \\
\text { Teixeira, Ellen Cynthia Fer- } \\
\text { nandes de Oliveira }\end{array}$ & $\begin{array}{l}\text { Percepções de representantes } \\
\text { de um comitê contra dengue } \\
\text { nas ações de educação em } \\
\text { saúde, Goiás, Brasil }\end{array}$ & $\begin{array}{l}\text { Revista Escola } \\
\text { de Enferma- } \\
\text { gem USP }\end{array}$ & Brasil & Português & LILACS \\
\hline
\end{tabular}




\section{artigo}

Costa, R.A.; Mendes, G.V.; Andrade, N.C.M.; Alves, M.E.F.; Siqueira, J.M., Farias, S.N.P.; Cavalcante, A.C.A.

A educação para saúde realizada por enfermeiros acerca das arboviroses no Brasil

Quadro 2. Caracterização dos artigos da RI quanto aos seus objetivos, tipo de estudo, resultados, conclusões e recomendações. Rio de Janeiro, RJ, Brasil, 2014 - 2018

\begin{tabular}{|c|c|c|c|c|c|}
\hline $\mathbf{N}^{\circ}$ & OBJETIVOS & TIPO DE ESTUDO & RESULTADOS & CONCLUSÕES & RECOMENDAÇÕES \\
\hline 01 & $\begin{array}{l}\text { Reunir e sintetizar } \\
\text { estudos sobre o tema, } \\
\text { com o fim de contribuir } \\
\text { para a maior compre- } \\
\text { ensão sobre educação } \\
\text { em saúde na prevenção } \\
\text { da dengue. }\end{array}$ & Estudo de revisão. & $\begin{array}{l}\text { Foram selecionados } 12 \\
\text { artigos, que sofreram divisão } \\
\text { temática nos temas: atuação } \\
\text { dos agentes de saúde, escola } \\
\text { como agente promotora de } \\
\text { saúde, papel da mídia e parti- } \\
\text { cipação da população. }\end{array}$ & $\begin{array}{l}\text { Há discrepância } \\
\text { entre as ações } \\
\text { governamentais e as } \\
\text { reais necessidades } \\
\text { da população. }\end{array}$ & $\begin{array}{l}\text { Implantação de uma } \\
\text { política de prevenção } \\
\text { e controle em que } \\
\text { as estratégias sejam } \\
\text { norteadas pelo co- } \\
\text { nhecimento social. }\end{array}$ \\
\hline 02 & $\begin{array}{l}\text { Analisar a atuação } \\
\text { dos Enfermeiros } \\
\text { das Estratégias de } \\
\text { Saúde da Família no } \\
\text { controle de dengue } \\
\text { e febre Chikungunya } \\
\text { nos municípios de } \\
\text { Parnamirim e Santa } \\
\text { Cruz/RN. }\end{array}$ & $\begin{array}{l}\text { Estudo exploratório } \\
\text { descritivo. }\end{array}$ & $\begin{array}{l}\text { Com os dados coletados, divi- } \\
\text { diu-se a ação da enfermagem } \\
\text { em duas categorias: "Educação } \\
\text { em saúde" e "Campanhas } \\
\text { higienistas e Informações". }\end{array}$ & $\begin{array}{l}\text { Há uma forte pre- } \\
\text { sença do modelo hi- } \\
\text { gienista/campanhis- } \\
\text { ta na fala e atuação } \\
\text { dos enfermeiros. }\end{array}$ & $\begin{array}{l}\text { A julgar pela } \\
\text { amostra pequena, } \\
\text { há necessidade de } \\
\text { mais estudos que } \\
\text { aprofundem o tema. }\end{array}$ \\
\hline 03 & $\begin{array}{l}\text { Revisar na literatura } \\
\text { as ações de controle, } \\
\text { prevenção e cuidados de } \\
\text { enfermagem aos indiví- } \\
\text { duos acometidos com o } \\
\text { vírus da dengue. }\end{array}$ & Estudo de revisão. & $\begin{array}{l}\text { A prevenção, quando bem de- } \\
\text { senvolvida, contribui significa- } \\
\text { tivamente para a redução dos } \\
\text { casos de dengue. O controle } \\
\text { através do combate é vital, e } \\
\text { os cuidados de enfermagem } \\
\text { são focados em reestabelecer } \\
\text { a saúde do indivíduo infectado. }\end{array}$ & $\begin{array}{l}\text { A eficiência nas } \\
\text { ações de preven- } \\
\text { ção e controle são } \\
\text { essenciais para a } \\
\text { redução do número } \\
\text { de casos da pato- } \\
\text { logia, e os cuidados } \\
\text { de enfermagem são } \\
\text { cruciais para o re- } \\
\text { estabelecimento da } \\
\text { saúde do paciente. }\end{array}$ & Não identificado. \\
\hline 04 & $\begin{array}{l}\text { Contribuir para o conhe- } \\
\text { cimento coletivo sobre o } \\
\text { mosquito Aedes aegypti, } \\
\text { através do desenvolvi- } \\
\text { mento de ações educati- } \\
\text { vas com escolares. }\end{array}$ & $\begin{array}{l}\text { Estudo qualitativo } \\
\text { de intervenção. }\end{array}$ & $\begin{array}{l}\text { Os alunos se mostraram } \\
\text { interessados e participati- } \\
\text { vos, visto que interviram na } \\
\text { prática proposta. }\end{array}$ & $\begin{array}{l}\text { Houve desinfor- } \\
\text { mação dos alunos } \\
\text { sobre os perigos da } \\
\text { dengue. }\end{array}$ & $\begin{array}{l}\text { Fortalecimento da } \\
\text { relação entre saúde } \\
\text { e escola na preven- } \\
\text { ção do mosquito da } \\
\text { dengue. }\end{array}$ \\
\hline 05 & $\begin{array}{l}\text { Avaliar o conhecimento } \\
\text { das enfermeiras da ESF } \\
\text { sobre a prevenção de } \\
\text { infecções pelo vírus zika } \\
\text { na consulta pré-natal }\end{array}$ & $\begin{array}{l}\text { Estudo qualitativo, } \\
\text { dedutivo, descritivo, } \\
\text { exploratório. }\end{array}$ & $\begin{array}{l}\text { Identificou-se insuficiência } \\
\text { de conhecimento para o } \\
\text { atendimento das deman- } \\
\text { das de ações educativas e } \\
\text { assistenciais à gestante para a } \\
\text { prevenção. }\end{array}$ & $\begin{array}{l}\text { Evidenciou-se que } \\
\text { as enfermeiras } \\
\text { precisam de melhor } \\
\text { preparo para atender } \\
\text { gestantes com pos- } \\
\text { sível infecção pelo } \\
\text { vírus Zika. }\end{array}$ & $\begin{array}{l}\text { Capacitação para } \\
\text { melhor atendimento } \\
\text { das demandas da } \\
\text { gestante relacionadas } \\
\text { ao vírus Zika. }\end{array}$ \\
\hline 06 & $\begin{array}{l}\text { Observar como ocorrem } \\
\text { as ações educativas de } \\
\text { prevenção e controle } \\
\text { da dengue em Goiás } \\
\text { Segundo a percepção } \\
\text { dos representantes do } \\
\text { Comitê Estadual de Mo- } \\
\text { bilização Contra Dengue. }\end{array}$ & Estudo transversal. & $\begin{array}{l}\text { Surgiram da análise três ver- } \\
\text { tentes: aspectos educacionais; } \\
\text { aspectos de gestão e envolvi- } \\
\text { mento da comunidade. }\end{array}$ & $\begin{array}{l}\text { Os representantes } \\
\text { do comitê reconhe- } \\
\text { ceram a importância } \\
\text { das ações educa- } \\
\text { tivas na prevenção } \\
\text { e no combate à } \\
\text { dengue. }\end{array}$ & Não identificado \\
\hline
\end{tabular}


enfermeiro frente ao ZIK e um estudo tem como tema o mosquito Aedes aegypti. Em relação ao tipo de estudo, prevaleceu o estudo de revisão, com um total de três, seguido de estudo de qualitativo, com um total de dois estudos.

No que diz respeito aos resultados, a maioria dos estudos discorre sobre o tema dividindo-o em vertentes importantes, como envolvimento da comunidade, ação da ESF e papel da enfermagem. Estudo ${ }^{(6)}$ mostra que alunos de Ensino Fundamental participativos em atividades lúdicas.

Quanto às conclusões, três estudos apresentaram a necessidade de melhoria em ações educativas. Um estudo mostra a importância de ações educativas para o enfrentamento da DEN, e o outro conclui que estudantes do Ensino Fundamental carecem de conhecimento sobre a doença.

Entre as recomendações encontradas, é esclarecida a necessidade de realização de mais estudos acerca do tema e maior capacitação da enfermagem para atuar no âmbito das arboviroses.

\section{DISCUSSÃO}

Tendo em vista que os flavivírus - arbovírus causadores da DEN, ZIK e FEBR - e os alphavírus - causadores da CHIK - são altamente incidentes no país, evidencia-se a importância de ações de prevenção e combate aos patógenos. Considerando-se que, de todas as doenças citadas, apenas a FEBR possui uma vacina como forma de profilaxia, podemos concluir que a forma mais eficaz de prevenção das arboviroses é a educação da população acerca do tema.

Neste interim, observa-se que a Enfermagem tem papel crucial na promoção de saúde relacionada às arboviroses. É de competência e incumbência da Enfermagem a realização de ações que visam a educação em saúde para a população. Em vista deste fato, torna-se evidente a importância de analisar a produção científica acerca do papel do enfermeiro como educador no combate e prevenção das doenças causadas por arbovírus.

No recorte temporal apurado, os resultados demonstraram que a maioria dos estudos é relacionada à DEN. A predomi-

\section{Com isto, combater}

este vetor é a

estratégia mais

utilizada pela

saúde pública

brasileira. Estudo ${ }^{(6)}$

afirma que todos

os profissionais

que atuam na ESF

têm papel crucial

na prevenção das

arboviroses, atuando

através da educação

em saúde, educação

permanente e

orientações à

população.

nância de estudos sobre esta patologia em detrimento às outras arboviroses ocorre, pois, a DEN é uma doença endêmica do Brasil e que acomete diversos países do mundo. Estudo(6) cita o fato de a Organização Mundial da Saúde (OMS) ter reconhecido a DEN como doença apenas no século $\mathrm{XX}$, quando diversos países do sudeste asiático sofreram endemias da versão hemorrágica da patologia.

Isto demonstra que a DEN está presente no mundo há décadas, sendo uma patologia reconhecidamente perigosa, diferentemente da CHIK e da ZIK, que se apresentaram como potencialmente maléficas nos últimos anos. Tal fato é apresentado por autores ${ }^{(7)}$ quando mencionam que o primeiro caso de CHIK diagnosticado no Brasil ocorreu em 2010 e, em 2014, os primeiros casos autóctones foram relatados no país, o que mais tarde tornaria a febre um problema de saúde pública brasileira.

Estudo $^{(8)}$ sobre a atuação da enfermagem na consulta de pré-natal de gestantes infectadas com ZIKA confirma que o ZIKA, assim como a CHIK, se disseminou muito recentemente no Brasil. Os autores discorrem sobre o fato de surtos de microcefalia no país começarem a ocorrer no ano de 2015, e como os enfermeiros da ESF, em sua maioria, estão despreparados para orientar e assistir estas gestantes, tendo em vista que, em sua formação acadêmica, tais doenças ainda não eram prevalentes.

Em todas as patologias citadas, o mosquito Aedes aegypti é o vetor, ou seja, é através da picada deste artrópode que os indivíduos são infectados pelos vírus da DEN, CHIK, ZIKA e FEBR. Com isto, combater este vetor é a estratégia mais utilizada pela saúde pública brasileira. Estu$\mathrm{do}^{(6)}$ afirma que todos os profissionais que atuam na ESF têm papel crucial na prevenção das arboviroses, atuando através da educação em saúde, educação permanente e orientações à população. Eles reiteram, ainda, que o mosquito se utiliza de utensílios que a população usa em seu dia a dia e que também podem fazer seus criadouros em locais com lixo ao céu aberto - o que é uma realidade em muitos locais do país, principalmente tratando-se de comunidades carentes. Tendo em vista que os locais de reprodução do vetor estão presentes, principalmente, nas moradias e no entorno do povo, orientar sobre a adequada conduta frente à esta realidade, tendo como fim empoderar os indivíduos de seus 
próprios cuidados e medidas de prevenção contra tais doenças, é de grande valor.

Não foram encontrados estudos dentro dos critérios de inclusão e exclusão que discorressem sobre a FEBR. Este fato é alarmante, tendo em vista que se trata de uma doença de alta periculosidade. Contudo, diferentemente das outras arboviroses, a FEBR conta com uma vacina como forma de profilaxia, facilitando a prevenção. De acordo com o Ministério da Saúde (MS), a aplicação de uma dose entre os nove meses e 59 anos de idade, em locais endêmicos - o que abrange a maioria do país - é o suficiente para uma eficaz imunização para o resto da vida - de $95 \%$ a $99 \%$-, além de ser uma vacina reconhecidamente segura. Entretanto, mesmo em presença de vacina, faz-se necessário orientar a população quanto à importância dela, para que os cidadãos busquem a mesma nos serviços de saúde ${ }^{(9)}$.

No âmbito da prevenção de arboviroses, é indiscutível o fato de que a educação em saúde tem papel fundamental. A Estratégia de Saúde da Família, que tem como princípio a proximidade com a população, é detentora da responsabilidade de promover esta educação. Como parte essencial da ESF, temos os Agentes Comunitários de Saúde que proporcionam elo entre a população e o serviço de saúde local, cujos quais são os profissionais que estão mais perto da comunidade, que conhecem os moradores, as vulnerabilidades e necessidades. Em seu estudo ${ }^{(9)}$, autores afirmam que os ACS desempenham a função de incentivar a adesão da população às práticas de prevenção. Contudo, os autores ainda declaram que, além dos Agentes Comunitários, faz-se importante a presença dos Agentes de Combate a Vetores $(\mathrm{ACV})$, tendo em vista que, dessa forma, os recursos seriam otimizados e possibilitaria maior envolvimento da comunidade no controle da DEN.

Estudo $^{(10)}$, por sua vez, afirma que a necessidade de planejamento de ações educativas que estimulam e orientam a população a efetivar o controle sem a necessidade direta dos ACS ou ACV, frisando assim a importância do empoderamento das pessoas sobre sua própria saúde. Os autores ainda reiteram que, além da atuação do controle de vetores, a Vigilância Epidemiológica é indispensável, tendo em vista que é através do sistema de notificações que é possível planejar ações e traçar projetos que atendam às demandas das diversas regiões endêmicas do Brasil.

A Enfermagem é a profissão referência tratando-se de promoção da saúde. Cabe ao enfermeiro orientar a população, planejar ações educativas e preparar a equipe para tal. Portanto, o enfermeiro deve constantemente estar estudando, atualizando-se e liderando a equipe para uma educação em saúde bem-sucedida. Além disto, conforme descreve estudo ${ }^{(10)}$, o enfermeiro atua na classificação de risco em serviços de urgência e emergência, o que demanda conhecimento fisiopatológico sobre as arboviroses.

Atentando-se para o papel do enfermeiro como educador em saúde, podemos observar que em muitos locais esta atribuição não tem sido realizada com êxito. Estudo $^{(7)}$ expõe que a população tem elevado conhecimento sobre a DEN, mas os níveis de instalação do mosquito permanecem altos. Para os autores, isto se dá pelo fato de, constantemente, as ações educativas terem um viés verticalizado, centralizado e unidirecional. Ações educativas realizadas desta forma podem ser fracassadas, pois este modelo impede a interação da população, dificultando a assimilação e internalização dos conhecimentos passados. Além disto, a troca de informações entre os enfermeiros e os usuários é crucial para o profissional identificar individualidades e vulnerabilidades, podendo atuar, assim, da forma mais efetiva possível para cada indivíduo.

Muitos enfermeiros utilizam do método tradicional de educação, realizando palestras e exposições para esse fim. Além disto, o modelo campanhista/higienista ainda é fortemente pregado para o combate do mosquito. No estudo, ele afirma que estes modelos estão enraizados na saúde pública, e que há a necessidade do desenvolvimento de novas estratégias educativas que visem a interação com a comunidade, e que se baseiem no conhecimento e experiencias populares ${ }^{(7)}$.
Dessa forma, observa-se que a enfermagem tem o grande desafio de desconstruir as ideias tradicionais previamente estabelecidas e desenvolver novas estratégias que se adequem a realidade dos usuários. Neste interim, estudo ${ }^{(7)}$ ainda cita as redes sociais como uma potencial ferramenta para educação em saúde, e que pode ser implementada pela ESF para compartilhamento de conteúdo, além de criação de grupos para usuários trocarem experiencias entre si.

Além de ações educativas em massa, a educação individualizada também é importante, principalmente durante as consultas de enfermagem. Estudo ${ }^{(8)}$ confirma este fato, ao discorrer sobre a conduta do enfermeiro com relação à prevenção $\mathrm{e}$ combate ao ZIKA nas consultas pré-natal. Os autores dizem que a enfermagem orienta de forma eficaz as gestantes quanto às medidas para evitar picadas de mosquitos, contudo, são ineficazes em outras orientações, como possíveis complicações da infecção pelo vírus. Como educador, o enfermeiro deve respeitar e lutar pelo direito do indivíduo de conhecer sua situação de saúde, atuando de forma ética frente aos sujeitos que estão sob seus cuidados. Os autores citam ainda que uma forma efetiva de promoção da educação em saúde é a criação de grupos de gestantes, em que estas compartilharão suas experiencias na presença de profissionais capacitados para tirar quaisquer dúvidas que tenham e fazer orientações necessárias.

Outra área de atuação importantíssima é a escola. Para autores ${ }^{(11)}$, a escola é um significativo local de articulação entre o serviço de saúde e a sociedade, sendo um ambiente favorável para os estudantes aprenderem, formarem cidadania e praticarem atitudes que os faça agir de forma mais inteligente. Portanto, as realizações de ações educativas em escolas são interessantes para prevenção das arboviroses. Estudo $^{(4)}$ discorre sobre estratégias educativas para crianças, nas quais o uso do lúdico é de grande valia, pois facilita o entendimento e interação dos escolares com os profissionais de saúde. Através do Programa Saúde na Escola, a equipe de enfermagem pode articular-se com as re- 
des de ensino e realizar ações educativas, respeitando a faixa etária e adequando sua conduta para cada uma delas. Enfatiza-se que, para o público crianças do Ensino Fundamental, a utilização do teatro como recurso lúdico é válida e, que em seu estudo, os alunos responderam positivamente à abordagem.

Por fim, é crucial o vínculo da enfermagem com a população. Estudo ${ }^{(1)}$ declara que os princípios da educação popular são de grande valor, e que é necessário, nas ações educativas, incentivar uma posição popular ativa diante do combate ao Aedes aegypti, e não apenas compartilhar informações. Para que a população modifique comportamentos, é preciso primeiro a mudança de valores. Para tal, faz-se necessário que o enfermeiro abandone a postura de superioridade e considere os conhecimentos populares como parte de sua estratégia.

\section{CONCLUSÃO}

Em vista dos altos índices de arboviroses no Brasil e a elevada demanda dos serviços de saúde - principalmente a Atenção Primária -, observa-se que a quantidade de estudos acerca da atuação do enfermeiro na educação em saúde para o enfrentamento dessas patologias é insuficiente. Averiguou-se que a maioria dos estudos discorre sobre a DEN em detrimento das outras arboviroses, o que indica uma deficiência na produção científica sobre estas doenças que estão acometendo fortemente a população brasileira. Além disto, aten- tando-se para a educação em saúde, constata-se que a equipe de enfermagem carece de aperfeiçoamento na realização de ações educativas eficazes.

Portanto, faz-se necessária a maior produção de estudos acerca da atuação da enfermagem neste âmbito, tendo em vista que o enfermeiro é o profissional central tratando-se de educação em saúde. No cenário da Atenção Primária, é fundamental a transição entre o modelo tradicional e verticalizado para um método mais centrado no indivíduo e em sua bagagem sociocultural, para o sucesso das ações educativas. É importante que o enfermeiro estimule em sua equipe esta transição, uma vez que é notória a necessidade de diferentes estratégias que se adequem à realidade da população nos dias de hoje.

\section{REFERÊNCIAS}

1. Lopes N, Nozawa C, Linhares REC. Características gerais e epidemiologia dos arbovírus emergentes no Brasil. Rev Pan-Amaz Saúde [Internet]. 2014 set [citado 2020 Fev 13]; 5(3):55-64. Disponivel em: http://scielo.iec.gov.br/scielo.php?script=sci_arttext\&pid=S2176-62232014000300007\&lng=pt.

2. Socorro Azevedo. Arboviroses de importância em Saúde Pública nas Américas e no Mundo [Internet]. Instituto Evandro Chagas, 2016 [acesso em 10 jan 2020]. Disponível em: https:// portalarquivos2.saude.gov.br/images/pdf/2016/agosto/02/ArbovEmergentes-Jul2016.pdf.

3. Ministério da Saúde, Secretaria de Vigilância em Saúde (BR) Vigilância em saúde no Brasil 2003|2019: da criação da Secretaria de Vigilância em Saúde aos dias atuais. Bol Epidemiol [Internet]. 2019 set [acesso em 10 jan 2020]; 50(n.esp.):1-154. Disponivel em: https:/portalarquivos2.saude.gov.br/images/ pdf/2019/setembro/25/boletim-especial-21ago19-web.pdf.

4. Marinho F (Orgs). Microcefalia no Brasil: prevalência e caracterização dos casos a partir do Sistema de Informações sobre Nascidos Vivos (Sinasc), 2000-2015. Epidemiol. Serv. Saúde [Internet], 2016 [citado 2020 Fev 13]. Disponivel em: http://scielo.br/pdf/ress/2016nahead/2237-9622-ress-S1679_49742016000400004.pdf

5. Ministério da Saúde, Secretaria de Vigilência (BR). Boletim Epidemiológico [Internet]. 2020 jan [acesso em 10 jan 2020]; 51(01). Disponivel em: https://portalarquivos2.saude.gov.br/images/ pdf/2020/janeiro/15/Boletim-epidemiologico-SVS-01.pdf.

6. Nicácio LA, Davim RMB, Oliveira MB et al. Intervenção educativa sobre o mosquito Aedes Aegypti. Rev enferm UFPE on line [Internet]. 2017 out [acesso em 29 set 2019];11(10):3771-7. Disponível em: https://pdfs.semanticscholar.org/dddf/45c9e-

\section{1e685acf30f89217f2f04144bcf.pdf}

7. Oliveira FLB, Millions RM, Costa MV, Almeida-Júnior JJ, Silva DGKC. Estudo comparativo da atuação do enfermeiro no controle de dengue e febre chikungunya. Saúde soc. [Internet]. 2016 Dec [cited 2020 Feb 13]; 25(4):1031-1038. Available from: http://www.scielo.br/scielo.php?script=sci_arttext\&pid=S0104-12902016000401031\&lng=en.

8. Affini AMS, Rocha SN, Silva SA da et al. Condutas das enfermeiras sobre o zika vírus na consulta pré-natal. Rev enferm UFPE on line [Internet]. 2017 dez [acesso em 25 ago 2019]; 11(Supl.12):5231-44. Disponível em: https://periodicos.ufpe.br/ revistas/revistaenfermagem/article/view/22918/25466.

9. Gonçalves RP, Lima EC, Lima JWO, Silva MGC, Caprara A. Contribuições recentes sobre conhecimentos, atitudes e práticas da população brasileira acerca da dengue. Saúde soc. [Internet]. 2015 Jun [cited 2020 Feb 13]; 24(2):578-593. Available from: http://www.scielo.br/scielo.php?script=sci_arttext\&pid=S0104-12902015000200578\&lng=en.

10. Santos GAC, Rosa JS, Matos EO, Santana ME. Dengue: prevenção, controle e cuidados de enfermagem - revisão integrativa da literatura 2008-2013. RBCS [Internet]. 2016 [citado em 13 fev 2020]; 20(1):71-8. Disponível em: https://periodicos.ufpb. br/ojs/index.php/rbcs/article/view/21374.

11. Cançado MSM, Barbosa MA, Teixeira RAG, Oliveira ESF. Percepções de representantes de um comitê contra dengue nas ações de educação em saúde, Goiás, Brasil. Rev Esc Enferm USP [Internet]. 2014 [citado em 13 fev 2012]; 48(Esp2):99-104. Disponivel em: http://www.scielo.br/pdf/reeusp/v48nspe2/pt_ 0080-6234-reeusp-48-nspe2-00094.pdf. 